\title{
Pensamento único e repetição em Schopenhauer
}

\author{
Single thought and repetition in Schopenhauer
}

\author{
Ruy de Carvalho \\ Professor da Universidade Estadual do Ceará (UECE) \\ E-mail: ruydec@uol.com.br
}

\begin{abstract}
Resumo: 0 artigo pretende discutir aspectos teóricos e metodológicos relativos à metafísica da natureza de Schopenhauer, objetivando mostrar que a noção de pensamento único abre espaço para a possibilidade de uma concepção de repetição que, por sua vez, torna possível vislumbrar uma teoria dos mundos possíveis em sua filosofia. Caso a intuição que baseia o artigo tenha algum valor, então, a cosmologia schopenhaueriana permitiria pensar noções tais como repetição e criação de maneira significativa para um debate com as cosmologias contemporâneas.
\end{abstract}

Palavras-chave: Metafísica; Pensamento único; Repetição; Mundos possíveis.

\begin{abstract}
The article intends to discuss theoretical and methodological aspects relating to Schopenhauer's metaphysics of nature, aiming to show that the notion of single thought makes room to the concept of repetition that, in turn, makes it possible to envisage a theory of possible worlds in his philosophy. If the intuition that bases the article has some value, then Schopenhauer's cosmology would allow thinking notions such as repetition and creating in a meaningful way to a discussion with the contemporary cosmologies.
\end{abstract}

Keywords: Metaphysics; Single thought; Repetition; Possible worlds.

\footnotetext{
* Conferência apresentada durante o VII Colóquio Internacional Schopenhauer, ocorrido na Universidade Federal da Bahia (UFBA), em Salvador, de 26 a 30 de outubro de 2015.
} 


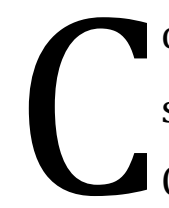
omo ler Schopenhauer? Como foi gestada, montada e apresentada sua obra capital, $O$ mundo como vontade e como representação? Quais referenciais teóricos (autores, obras) devemos conhecer para bem compreender a significação profunda de seu pensamento? Aparentemente, nada seria mais fácil do que responder a tais indagações. 0 próprio autor já as teria solucionado, explícita e claramente, tanto em sua tese doutoral (edição de 1847), como em $O$ mundo (1818 e 1844) e nos Complementos (1844) a este. Pretende-se, no entanto, mostrar que, não obstante a auto-interpretação schopenhaueriana, ainda subsistem problemas teórico-metodológicos sérios a serem resolvidos para uma boa compreensão de sua obra.

Nos prefácios de 1818 e 1844, assim como no capítulo 17 dos Complementos e no $§ 14$ dos Fragmentos para a história da filosofia, no primeiro volume dos Parerga, Schopenhauer apresenta quatro condições que devem ser satisfeitas por todo aquele que levante uma séria pretensão de inteligibilidade daquilo que será exposto: 1) que se compreenda que se trata de um pensamento único (einziger Gedanke) e não de um sistema de pensamento (System von Gedanken); 2) que se tenha conhecimento de sua tese de doutorado intitulada Sobre a quádrupla raiz do princípio de razão suficiente. Um ensaio filosófico (1813 e 1847); 3) que se tenha compreendido (feito sua "operação de catarata") a obra de Kant; 4) que se tenha freqüentado a "escola do divino Platão" e , para estar preparado da melhor maneira possível, que se tenha iniciado na sabedoria das Upanixade(s), dos Veda(s).

É ainda o próprio autor quem nos comunica, nos textos acima referidos, o que ele entende por pensamento único, pensamento fundamental (Grundgedanke). Trata-se de uma mesma idéia que, devido às limitações inerentes a toda e qualquer comunicação conceitual, apresenta-se decomposta em partes mas que, não obstante, deve ser apreendida: 1) em sua perfeita unidade (vollkommenste Einheit); 2) em sua coesão orgânica (em que cada parte conserva e é conservada pelo todo; em que este é esclarecido por aquelas e em que a menor das partes é ininteligível sem o todo); 3) na contradição em que nela se encontram forma e conteúdo (a lógica da exposição difere da lógica da compreensão, em se tratando de um pensamento único); 4) em seus diferentes lados (metafísica, ética, estética); expostos a partir de dois pontos de vista e quatro considerações (duas para cada ponto de vista); 5) como chave de acesso ao significado de todos os fenômenos do 
mundo, ao sentido do mundo e à decifração do enigma do mundo; 6) como tendo surgida e sido exposta pela via analítica e não sintética, i.e., por apoiar-se numa apreensão intuitiva de um mesmo objeto visto por diferentes lados e, assim, por ser ascendente: ir do conhecimento intuitivo ao abstrato, e não o inverso; não ultrapassando, portanto, o mundo das experiências (externa e interna).

Para o autor de $O$ mundo, o pensamento único seria, então, a expressão de uma filosofia que pretende explicitar, desvelar o sentido profundo do real e apresentá-lo por meio de conceitos; em outros termos: decifrar o enigma do mundo e expressá-lo abstratamente, conceitualmente. Schopenhauer, assim, orienta o leitor sobre a maneira de lê-lo; sobre o ponto de partida de seu pensamento (o conhecimento intuitivo), sobre a forma que este deve adquirir; sobre o modo como as diferentes partes de sua filosofia devem ser articuladas e, indiretamente, sobre os critérios a serem seguidos numa possível leitura crítica de sua obra.

Esta ideia de um pensamento único, além de poder ser interpretada negativamente, i.e., como aquilo que não se identifica como um sistema de pensamento de feição kantiana, pode ser ainda alcançada por meio de uma análise da noção de movimento nas filosofias de Kant e Schopenhauer. Caso comparemos os Princípios metafísicos da ciência da natureza com $O$ mundo, veremos que a noção de movimento passa de determinação da subjetividade transcendental para simples fenômeno da Vontade. Isto aponta para uma modificação, empreendida por Schopenhauer, no sentido mesmo do conceito kantiano de representação. Está em jogo aqui, consequentemente, o estatuto da noção de coisa em si. Como para o autor de $O$ mundo, o significado de representação deve ser pensado em co-relação com o de Vontade, então já na ideia de movimento estaria pré-figurada a ideia de um pensamento único, pois é fundamental que se possa pensar uma mesma e una Vontade atuando tanto na natureza, no belo, quanto na moral. Isto é dito mais clara e explicitamente no segundo volume de 0 mundo, no capítulo 23, Sobre a objetivação da Vontade na natureza carente de conhecimento, em que Schopenhauer elenca os dois primeiros e fundamentais passos (Schritt) para se compreender a sua filosofia: o primeiro passo sendo a separação toto genere entre Representação e Vontade, sendo aquela secundária em relação a esta; e o segundo passo, a 
compreensão de que uma mesma e una Vontade objetiva-se na natureza através de forças naturais que disputam uma mesma matéria.

Segundo Schopenhauer, somente o método analítico garante que a filosofia não ultrapasse o mundo dado na experiência, mas esclareça o que ele é, já que o decompõe em suas partes constitutivas. Aqui, a filosofia não deve se apoiar em simples conceitos abstratos, não pressupor arbitrariamente nenhum conteúdo como dado, mas partir do próprio mundo conhecido intuitivamente; não deve desenvolver-se por demonstrações e raciocínios meramente lógicos, mas por uma apreensão intuitiva de um mesmo objeto que é observado por diferentes lados, i.e., deve partir do mundo real e de todos os seus fenômenos considerados pela consciência. Em tal procedimento a unidade do pensamento é garantida pelo seu espelhamento da realidade, a qual, segundo Schopenhauer, concorda sempre consigo mesma. Parece ser também o método analítico que impede a filosofia de perguntar por uma causa eficiente ou final do mundo; de investigar de onde (woher) vem ou para quê (wozu) existe o mundo. Segundo Schopenhauer, em filosofia, o "por quê" deve estar submetido ao "quê".

Quer isto dizer que a filosofia não deve deixar resto e que, portanto, o método analítico e o pensamento único mantêm uma íntima relação, uma vez que somente aquele seria capaz de satisfazer as altas pretensões deste? De todo modo, cabe então perguntar se tal chave de leitura (pensamento único) e se o método analítico realmente são suficientes para tornar plenamente compreensível a obra do autor de $O$ mundo. Esta ideia de uma chave capaz de abrir o acesso à significação do mundo tem uma inspiração kantiana e vincula-se à tentativa de Schopenhauer de solucionar o impasse apresentado por Kant na Crítica do juízo.

0 fato é que alguns problemas relevantes parecem surgir. No que se refere ao caráter orgânico de tal pensamento, Schopenhauer nos surpreende ${ }^{1}$ no final do

\footnotetext{
1 É verdade que, no prefácio de 1818, ele nos diz que no seu pensamento único "o começo pressupõe o fim quase tanto quanto o fim o começo, e precisamente assim cada parte anterior pressupõe quase tanto a posterior quanto esta aquela. Digo "quase", pois de modo algum é absolutamente assim." No entanto, este "quase" parece ser um problema exterior (do leitor, mas aqui reside nosso problema), pois no que diz respeito ao conteúdo mesmo da obra, há uma "intercoesão de todas as partes". Seja como for, no § 54 do livro IV, lemos que se “(...) toda esta obra é apenas o desdobramento de um pensamento único, segue-se que todas as suas partes não apenas tem a mais íntima ligação entre si -e não meramente cada uma delas está numa relação necessária com as imediatamente anteriores ,e, desta forma, apenas estas são pressupostas na memória do leitor, como na caso de todas as filosofias consistindo simplesmente numa série de inferências -,
} 
$\S 54$ do quarto livro de $O$ mundo, quando afirma que: "a análise de nosso pensamento único em várias considerações era o único meio para sua comunicação, apesar de semelhante forma não lhe ser essencial [wesentliche], mas artificial [kunstliche]"2.

Mas então como se constrói este artifício 3 ? E o método sintético, por ele tão criticado em Spinoza, pode também ser compreendido como contingente, não necessariamente ligado ao conteúdo da Ética, mas apenas "um meio para sua comunicação" mais rigorosa? Como se relacionam, então, método e conteúdo na filosofia de $O$ mundo? Como entender a rudeza de Schopenhauer quando da construção de filosofias como sistemas de pensamento ${ }^{4}$ ?

Em todo caso, parece que o pensamento único poderia ser comunicado de uma outra forma e, então, caberia a pergunta: será que esta outra forma (sintética) foi efetivamente utilizada por Schopenhauer em $O$ mundo e, em caso afirmativo, onde e com que intenção, para resolver que problemas?

Seja como for, o pensamento único pressupõe ainda a existência de uma simetria e complementaridade entre os livros de sua obra capital. Porém, se comparamos suas partes, vemos que a simetria não parece ser total, pois o quarto livro desdobra-se em duas partes (auto-afirmação e auto-negação da vontade), o que não nos parece acontecer nos outros três livros. Seria o caso de se perguntar se a chave (pensamento único) utilizada por Schopenhauer, mesmo que não explique a estrutura da obra (mas que se aplique a toda ela), não estaria necessariamente ligada apenas aos livros pares, principalmente ao segundo, àquele em que é

mas também cada parte da minha obra é aparentada às outra e as pressupõe" (SCHOPENHAUER, A. SW, I, § 54, p. 337).

${ }^{2}$ Cf. SCHOPENHAUER, A. SW, I, p. 394.

${ }^{3}$ Sobre esse problema do pensamento único como chave de leitura de 0 mundo, cf. Prefácio a Sobre o fundamento da moral. In: SCHOPENHAUER, A. SW, III.

${ }^{4}$ No Prefácio da segunda edição de 0 mundo, vemos Schopenhauer dizer: "O leitor sempre me encontrará no ponto de vista da reflexão (Standpunkt der Reflexion), i.e., da deliberação racional, nunca no ponto de vista da inspiração (Inspiration), chamado intuição intelectual (intellektuelle Anschauung) (Fichte e Schelling), ou do pensamento absoluto (absolutes Denken) (Hegel), cujos nomes mais corretos são: mundo aéreo (Windbeutelei) e charlatanismo." Cf., SW, I, p.17. Mais ainda, pois para ele os sistemas de pensamento pós-kantianos são tão somente uma reedição da teologia racional ou especulativa da escolástica e da modernidade, em substituição aos quais ele diz que "gostaria de oferecer despretensiosamente à reflexão desses senhores [Herbart, Krug, Fries, Scleiermacher, Schelling e Hegel] o fato de que, embora a teologia possa ser de grande valor, conheço algo que ainda é sempre mais valioso, a saber, a honestidade (Redlichkeit) - a honestidade, tanto no modo de vida como no pensar e ensinar; eu não a venderia por nenhuma teologia" (grifo nosso). Cf. SCHOPENHAUER, A. SW, IV, Sobre a filosofia universitária, p. 233. 
apresentada sua metafísica da natureza. Isto porque nos outros livros é relativamente fácil identificar as influências de Schopenhauer, pois o livro primeiro é espiritualmente kantiano, o terceiro é fundamentalmente platônicoschellingniano, o quarto é kantiano e védico; mas e o segundo? Começa kantiano (teoria da representação) ${ }^{5}$, termina platônico (teoria das Ideias) com escalas na escolástica aristotélica (forma substantialis) e na filosofia schellingniana (teoria das objetivações da Vontade, polaridade, etc); mas de onde vem o procedimento analógico e a irracionalidade e voracidade inelimináveis da Vontade? Seria ele (livro II) mais verdadeiramente schopenhaueriano que os outros ${ }^{6}$ ?

Acontece que é exatamente na relação entre o segundo e os demais livros que o problema do método aparece de forma mais urgente. Parece claro que na solução dos enormes problemas colocados pelo procedimento analógico, Schopenhauer tenha seguido um caminho analítico. Mas isso já não é tão claro se visualizarmos o conjunto da obra, começando por sua divisão, que parece sintética. Além de que, toda problemática em torno dos processos de objetização (termo nosso) e objetivação da Vontade parece oscilar entre uma postura sintética e outra analítica.

\section{Metafísica e repetição}

Logo na abertura do segundo livro de $O$ mundo, Schopenhauer delimita seu campo de interesse. Trata-se, agora, de investigar o conteúdo ou a significação da representação. A primeira coisa que chama a atenção na passagem do primeiro para o segundo livros da obra é a mudança dos verbos. Agora, o objetivo do autor é compreender, apreender o sentido da representação. Difícil não lembrar do empreendimento crítico e da necessidade de passar de um saber para um dever por meio de um esperar. Quando Kant pergunta: se eu sei o que posso, e faço o que devo, então o que me é permitido, legitimamente, esperar (A806; B834)? Ele pode

\footnotetext{
${ }^{5}$ Mas é aqui que Schopenhauer comete seu "parricídio" em relação a Kant, com o procedimento analógico como forma de acesso à coisa-em-si. De fato, o "parricídio" já se anunciava no livro primeiro e seu complemento, com a fisiologização da teoria da representação de Kant, assim como, pela influência de Platão e das Upanixade, a identificação entre fenômeno e aparência (sonho) entre mundo fenomênico e mundo ilusório etc.

${ }^{6}$ Quanto ao problema das fontes, já vimos que, apesar de Schopenhauer ter negado ou diminuído a importância da filosofia de Schelling na gênese e construção de seu pensamento (cf. Fragmentos, $\S 14$, p. 121), a tese a pouco publicada de Jair Barboza nos parece desmenti-lo de modo considerável.
} 
levantar tal interrogação porque nunca abandona a pátria da razão. Daí que poderíamos reformular a questão kantiana mais ou menos assim: se, após a negatividade da primeira Crítica, eu sei até onde e como posso ir com a razão, e se descobri, na natureza da razão, um dever que todo ser racional tem que querer, enquanto ser racional, então o que me é permitido esperar? A passagem é quase imediata, claro, após a crítica racional da razão. Em uma palavra: se a Crítica da razão pura investiga as condições do conhecimento do que acontece (Erscheinung), mas isso em nada nos auxilia na direção de nossa conduta no mundo quotidiano, uma vez que nesse último o que importa é o que fazemos numa situação dada, ou como interpretamos o que julgamos importante para agir no mundo, então a única utilidade de uma tal Crítica estaria em que, com base na mesma poderíamos, positivamente, colocarmo-nos no reino do sentido e do valor. Ora, é isso mesmo que a Crítica abre, a possibilidade de, racionalmente, pensarmos imperativos de ação que não se coloquem em choque com os resultados negativos oriundos dela.

A passagem da explicação para a compreensão, via Crítica, não oferece maiores problemas porque entre o que há para explicar (fenômenos) e o que se tem que descobrir para compreender (lei moral) não existe uma diferença toto genere. Assim, se entre o saber e o crer, entre o ser e o dever, entre o conhecer e o pensar, entre o fenômeno e a coisa em si não há um abismo, a comunicação é mais fácil de ser pensada. Agora, se o conhecer e o pensar estão ambos do lado da Representação, então como transitar desta para a Vontade? Como passar da explicação para a compreensão? Em Kant, a distinção entre fenômeno e coisa em si pede a separação entre conhecer e pensar, explicar e compreender; mas em Schopenhauer, tanto o conhecer quanto o pensar estão do lado da representação. Como fazer, então, a passagem (Übergang), como operar o trânsito (Übertragen)?

Os seis primeiros parágrafos do segundo livro de $O$ mundo pretendem responder a esta difícil pergunta. No $§ 17$, logo no início, ficamos sabendo do que se trata: o que interessa é, examinando a representação intuitiva, conhecer o seu conteúdo (Inhalt), sua significação própria (eigentliche Bedeutung), mais precisamente, o sentido da representação intuitiva (die Bedeutung jener anschaulichen Vorstellung ${ }^{7}$. Sabemos também que, supostamente de maneira

${ }^{7}$ Cf. SCHOPENHAUER, A. SW, I, § 17, p. 151. 
kantiana, o conteúdo e a significação procurados residiriam naquilo que se encontraria no fundamento de toda representação, uma espécie de "objeto" que fosse distinto desta. Ora, como não podemos sequer pensar, segundo Schopenhauer, um objeto que não seja representação, já que objeto, fenômeno e representação são sinônimos, então semelhante busca conteria um vício de origem. Devido a isso, no $§ 18$, surge a base para o procedimento analógico a ser tentado: a distinção conceitual entre sujeito (Subjekt) e indivíduo (Individuum). Como nos diz Schopenhauer, sem corpo, somente com a cabeça, como uma espécie de anjo (Engelskopf ohne Leib), jamais nos apossaríamos da significação (moral?) do mundo.

De fato, seria impossível encontrar a significação procurada deste mundo, dado a mim simplesmente como a minha representação, ou então a passagem (Übergang) deste mundo, enquanto mera representação do sujeito que conhece, àquilo que pode estar fora da representação, se o próprio filósofo não fosse nada mais do que o puro sujeito que conhece (uma cabeça de anjo alada destituída de corpo). Mas, com efeito, ele tem a sua raiz no mundo: enquanto individuo, faz parte dele; o seu conhecimento é o sustentáculo e condição da representação do mundo inteiro; mas este mesmo conhecimento tem como condição necessária a existência de um corpo, cujas modificações são, como vimos, o ponto de partida do entendimento para a intuição deste mundo ${ }^{8}$.

A tese é conhecida: "a palavra do enigma (Rätsels) é dada (gegeben) ao sujeito do conhecimento (Subjekt des Erkennens) que aparece como indivíduo: e esta palavra chama-se vontade" ${ }^{\prime}$. Desta, ele obterá a chave (Schlüssel) para compreender o verdadeiro significado de seu próprio fenômeno e de sua engrenagem interior (innere Getriebe), de seu ser (Wesen) e de seu agir (tun). A grande condição para que tudo isso aconteça é, segundo Schopenhauer, que se entenda a identidade do indivíduo com o seu corpo e a duplicidade de acesso e, portanto, de conhecimento do sujeito em relação ao seu corpo: por um lado, objeto entre objetos (ponto de vista objetivo, de fora) e, por outro, vontade, como algo dado e conhecido imediatamente (ponto de vista subjetivo, de dentro). Isto irá implicar a simultaneidade do querer e do agir:

${ }^{8}$ Cf. Idem, I, § 18, p. 156-7.

${ }^{9}$ Cf. Ibidem, p. 157. 
o ato da vontade e a ação do corpo não são dois estados diferentes, conhecidos objetivamente e vinculados pelo nexo causal; tampouco encontram-se na relação de causa e efeito; mas são uma única e mesma coisa, apenas dada de duas maneiras totalmente diferentes, uma vez imediatamente e outra na intuição do entendimento. A ação do corpo nada mais é senão o ato da vontade objetivado, i.e., que apareceu na intuição ${ }^{10}$.

Igualmente, tornará possível conceber o corpo como, por um lado, objeto imediato (livro I) e, por outro, como objetidade da Vontade (Objektität des Willens). Daqui surge o núcleo da argumentação de todo o segundo livro: a tese da objetivação da Vontade (em graus determinados) e a possibilidade da analogia, da passagem entre Representação e Vontade; cuja primeira formulação diz: "a vontade é o conhecimento a priori do corpo, assim como o corpo é o conhecimento a posteriori da vontade (der Wille ist die Erkenntnis a priori des Leibes und der Leib die Erkenntnis a posteriori des Willens)"11.

Se o ato da vontade não se separa da ação do corpo, então não deve existir separação entre o conhecimento de minha vontade e o conhecimento do meu corpo, com a ressalva de que somente conheço os atos de minha vontade no tempo, não todos de uma vez, mas um após o outro logo, a posteriori. Portanto, o corpo será o campo de batalha em que se decidirá a viabilidade de uma metafísica da Vontade. Corpo como condição da metafísica, eis o que se trata de pensar.

Vê-se, agora, a razão da estratégia adotada na tese quando da postulação de um milagre verdadeiramente filosófico. Precisamente, se posso compreender a intimidade da lei de causalidade por meio de uma analogia com a lei de motivação, então, talvez também possa esperar compreender, analógica e mais profundamente, o segredo da totalidade do mundo como representação, sua significação mais misteriosa. Porém, Schopenhauer, já aqui, lembra de que todo seu esforço não passa de uma analogia e que, rigorosa e exaustivamente, a identidade da vontade com o corpo não pode ser demonstrada (bewiesen), apenas atestada (nachgewiesen) ${ }^{12}$. Podemos antecipar que, apesar de todo o esforço e

\footnotetext{
10 Cf. Ibidem, p. 158.

${ }^{11}$ Cf. Ibidem, p. 158.

12 É nessa passagem que Schopenhauer identifica aquele milagre por excelência, a que nos referimos acima (kat exokhén), como uma verdade filosófica (philosophische Wahrheit), distinta de todas as elencadas na tese sobre o princípio de razão suficiente. Na verdade, ele afirma que se pode expressar de várias maneiras semelhante verdade misteriosa: "meu corpo e minha vontade são uma
} 
complexificações empreendidos por Schopenhauer, de fato, o procedimento analógico continuará, pensamos, para sempre problemático. Resta saber se isso seria a última palavra sobre o assunto, i.e., se o que realmente o interessa é explicar fenômenos, analogamente, à Vontade ou encontrar um lugar, como diria Kant, não para a crença, mas para o mistério, o inexplicável, o silencioso.

No $§ 19$ é a primeira vez, em $O$ mundo, que aparece, explicitamente, o procedimento analógico; ele surge como opção a uma espécie de argumentação apagógica, elêntica, como exclusão por absurdo da tese oposta, a posição denominada por Schopenhauer de egoísmo teórico (theoretischen Egoismus) o qual, por ser tão irrefutável quanto indemonstrável, somente poderia ser "superado" por um procedimento como o analógico. 0 procedimento é espantosamente simples. Consiste, basicamente, em partir do duplo conhecimento que temos de nosso corpo, ambos na esfera da representação, i.e., o imediato (interno, de dentro) e o mediato (externo, de fora), e afirmar que, de duas uma: ou somos o único ser no mundo que deve ser considerado como Representação e Vontade (egoísmo teórico), já que sabemos disso direta ou indiretamente; ou, diferentemente, aquilo que sabemos que somos, também temos que estender, analogamente, ao restante dos seres do mundo. Portanto, ou tudo no mundo é representação e vontade, ou somente nós, seres humanos, assim o somos; todo o resto sendo meras representações (bloße Vorstellungen), meros fantamas (bloße Phantome). Trata-se, essencialmente, de uma utilização daquele mistério verdadeiramente filosófico, como uma chave de abertura da significação da essência de todo fenômeno à compreensão humana.

Surpreendente procedimento! Primeiro, fica claro que sem o milagre da tese e sem a descoberta de que aquele é uma verdade filosófica indemonstrável, não haveria analogia, pelo menos não a acima apresentada, uma vez que esta apóia-se na tese da duplicidade de conhecimento que temos acerca de nosso próprio corpo e, portanto, no duplo acesso - mediato e imediato - que temos ao mesmo. Segundo, surpreende encontrar aqui aquilo que Schopenhauer censurava em Kant, o uso do tem de e deve ser em argumentações importantes; é interessante saber que aquilo que os corpos são, além de representações do sujeito, tem de ser o mesmo que 
reconhecemos, imediatamente, em nós como vontade. Terceiro, por saber que, excetuando a representação e a vontade, nada mais existe de conhecido nem pensável; supor que a representação é conhecida e a vontade é pensável não ajuda muito, já que a vontade de que se fala aqui não é a Vontade, mas sim aquela a que se tem acesso no tempo, portanto via representação, i.e., a distinção kantiana (BXXVI) entre o que se pode conhecer (erkennen) e aquilo que se deve poder pensar (müssen denken können) não deveria poder ser aplicada aqui, uma vez que a distinção em questão não é aquela postulada entre fenômeno e coisa em si (Representação e Vontade, segundo Schopenhauer), mas sim entre duas perspectivas acerca da representação, uma considerada objetivamente, e outra subjetivamente.

De qualquer maneira, o que interessa a Schopenhauer parece claro, sobretudo se continuamos a leitura da obra. O que lhe exige toda a atenção é mostrar que o corpo mesmo, todo o corpo (ganze Leib) tem de ser apenas minha vontade tornada visível, i.e., "tem de ser (muß...sein) a minha vontade mesma na medida em que esta é objeto intuído (anschauliches Objekt), representação da primeira classe"13. Vê-se que as dificuldades vão aumentando, pois se na tese a condição da analogia é um milagre, aqui, na explanação deste, temos que lançar mão de uma verdade filosófica indemonstrável e de um argumento por absurdo de legitimidade duvidosa. Apesar disso, no § 21, Schopenhauer nos surpreende quando diz que aquilo que na tese era o correlato subjetivo da vontade, ou seja, a consciência de si, agora é afirmado do sentimento (Gefühl), saber in concreto daquele milagre e da verdade filosófica14. Ora, sabemos pelo livro I ( $(11)$ que o sentimento é uma noção negativa e que aponta para o fato de a razão, simplesmente, ainda não poder conceber um conteúdo volitivo dado aplicando, então, o conceito de sentimento; o fato é que tanto no $\S 21$ quanto no $\S 18$ aparecem a noção de sentimento, como se a razão pudesse penetrar em conteúdos irracionais e os re-significar em forma de saber. Isto não deixa de ser surpreendente, visto o papel secundário da razão na filosofia de Schopenhauer. Em

${ }^{13}$ Cf. SCHOPENHAUER, A. SW, I, § 20, p. 167.

${ }^{14}$ Cf. Ibidem, p. 169. 
todo caso, isso não parece ter sido levado a cabo por ele ${ }^{15}$.

A analogia, não obstante os problemas a ela relacionados, será utilizada por Schopenhauer em todo o restante do livro II. No $§ 22$ deste ele defende, mais fortemente ainda, aquilo que chama de ampliação (Erweiterung) do conceito de vontade e afirma que estaria sempre em incompreensão (immerwährenden Mißverständnis) de sua filosofia quem não estivesse em condições de apreender o necessário e, segundo ele, justificado alargamento da noção de vontade; daí ele poder afirmar não ter sido casual a escolha da palavra Vontade para expressar a essência de todas as coisas, como se tal nome apenas fosse o indicador de algo desconhecido; tudo ao contrário pois, segundo ele, o termo é uma espécie de palavra mágica (Zauberwort) capaz de nos desvelar (aufschließen) a essência mais íntima (innerste Wesen) de todas as coisas e, além disso, por meio de um conhecimento tal que aquilo que conhecemos como vontade, sabemos e compreendemos melhor que qualquer coisa (besser Wissen und verstehn als sonst irgend etwas) ${ }^{16}$.

Vamos ao que está, realmente, em jogo na descoberta do milagre na tese de 1847 e da verdade filosófica em $O$ mundo e o porquê da complexificação do problema no segundo volume deste. Em uma palavra: trata-se da legitimidade não apenas da metafísica da natureza mas, ao acreditarmos no que é dito nas Preleções de 1820, da metafísica mesma. Pelo menos a partir de 1820, metafísica e metafísica da natureza são termos sinônimos, segundo Schopenhauer, tautológicos ${ }^{17}$. A vontade, correlato objetivo da consciência de si na tese doutoral, e a causalidade, correlata do entendimento, devem articular-se para que a passagem (Übergang) da percepção interna e imediata (innern unmittelbaren Wahrnehmung) da vontade em nós para a teoria do mundo como Vontade seja pensável, compreensível.

Para isso, é claro, não basta a analogia entre a quarta e a primeira classes do princípio de razão suficiente, pois é necessário que uma mesma e única Vontade possa se expressar em diferentes formas e diferentes graus em todos os seres, orgânicos e inorgânicos, do mundo; sem isso, não se poderia esperar construir uma

\footnotetext{
15 Quem procura explorar esta hipótese na tentativa de solucionar o problema da passagem ou analogia é Margit Ruffing. Cf. RUFFING, M. O sujeito do conhecimento - o objeto da ação: a "passagem", identidade e diferença na filosofia de Arthur Schopenhauer, pp.11-28. Apesar de interessante, pensamos que a hipótese de Margit precisaria de uma maior comprovação textual. ${ }^{16}$ Cf. SCHOPENHAUER, A. SW, I, § 22, p. 172.

${ }^{17}$ Cf. SCHOPENHAUER, A. Vorlesungen, Metaphysik der Natur, pp. 54-60.
} 
metafísica imanente em relação a um só e mesmo mundo, considerado de dois pontos de vista. Precisamente, ainda falta a teoria da objetivação da Vontade e, óbvio, que se possa encontrar um correlato objetivo, do lado da representação em geral (não de uma representação particular, i.e., um objeto), uma condição fundamental e garantidora de toda a objetividade dos objetos e, assim, que acompanhe as distintas etapas de objetivação de uma Vontade una em seus diferentes graus; schopenhauerianamente: é preciso encontrar - caso se pretenda realizar uma analogia rigorosa - um correlato objetivo para o ser subjetivo tomado como coisa em si ou Vontade; a analogia somente poderá funcionar com a introdução das noções de Idéia e matéria (Materie) do lado da representação o que irá ocasionar, no mínimo uma complexificação na teoria da representação de Schopenhauer18. Vê-se, assim, que todo o problema das polêmicas noções de Idéia e matéria na obra de Schopenhauer está, visceralmente, vinculado à necessidade de justificar seu projeto idealista por meio de um procedimento analógico.

Na segunda metade do livro II de $O$ mundo, Schopenhauer apresenta a tese de que a Vontade tem objetidades imediatas (como o corpo, por exemplo) e estas apresentam graus ("Nos graus mais altos de objetidade da Vontade..."19) variados. Segundo ele, para realizar o que lhe interessa neste livro, i.e., compreender a significação das representações, é preciso poder explicar como o mundo da Representação está estruturado.

O que ocorre é que a Vontade se objetiza em objetidades imediatas e, estas, se objetivam - por meio do princípio de causalidade - nos diferentes seres existentes no mundo. 0 importante, aqui, é a tese de que uma única e mesma Vontade objetiza-se em Idéias (como as forças naturais ou os caracteres animais), as quais devem ser compreendidas como modelos inalcançáveis (unerreichten Musterbilder) ou formas eternas das coisas (ewigen Formen der Dinge).

Uma pergunta que se poderia fazer: seria possível imaginar que uma única e mesma Vontade se objetivasse de maneiras diferentes configurando, por assim dizer, mais de um mundo possível? Claro, na objetivação das Idéias em fenômenos, ocorre uma luta sanguinária pela posse da matéria. Na entrada em cena daqueles ocorre uma guerra fratricida pela única e mesma matéria existente. Na verdade, é

${ }^{18}$ Sobre isso, cf. BRANDÃO, E. A concepção de matéria na obra de Schopenhauer, 2009.

19 "Auf den obern Stufen der Objektität des Willens..." (SCHOPENHAUER, A. SW, I, § 26, p. 197). 
exatamente por isso que a causalidade será chamada de norma (Norm) reguladora neste processo de objetivação pois, caso contrário, nenhum fenômeno cederia lugar ao outro. Assim, Schopenhauer pretende poder articular a lei de causalidade com a lei de permanência da substância, contanto que, vê-se logo, se possa conceber a matéria (Materie) como substância. Mas em todo o caso, seria possível pensar a eterna repetição da objetivação da Vontade na pluralidade de seus fenômenos como uma forma de criação de mundos possíveis? Como ele nos diz:

Porque a totalidade dos fenômenos das Idéias eternas remete a uma única e mesma matéria (eine und dieselbe Materie), tem de (mußte) existir uma regra (Regel) do seu aparecer e desaparecer (Ein-und Austritts sein), do contrário nenhum deles cederia lugar ao outro. Por causa disso, a lei de causalidade (Gesetz der Kausalität) está intimamente ligada à lei de permanência da substância (Gesetz der Beharrlichkeit der Substanz). Ambas adquirem significação (Bedeutung) uma da outra20.

A objetivação de uma única e mesma Vontade numa pluralidade de fenômenos pela mediação das Idéias e através da supervisão da causalidade somente é possível com a condição de que tal manifestação - tornar-se representação - da Vontade ${ }^{21}$ tenha como suporte uma única e mesma matéria (Materie). Essa multiplicidade de Idéias disputando uma mesma matéria é que levará à interpretação schopenhaueriana de que "a Vontade de vida crava continuamente os dentes em sua própria carne"22, i.e., ele vê na natureza uma espécie de espelho a refletir, eternamente, uma disputa (Streit) originária e primeva; em uma palavra: o espetáculo agônico que podemos observar na natureza nada mais seria que "a revelação (Offenbarung) da discórdia essencial (wesentlichen Entzweiung) da Vontade consigo mesma"23. Percebe-se, então, como a analogia, com o apoio da teoria da objetivação da Vontade e da tese da inteligibilidade reversa, pode fornecer uma explicação - nada otimista - por um lado, do funcionamento das relações entre seres orgânicos e inorgânicos na

\footnotetext{
${ }^{20}$ Cf. SCHOPENHAUER, A. SW, I, § 26, p. 202.

${ }^{21}$ Segundo Schopenhauer, "todo o conjunto (trata-se do corpo humano) é, em última instância (zuletzt), Vontade que se converte a si mesma em Representação (der sich selber Vorstellung wird)..." (SCHOPENHAUER, A. SW, II, cap. 20, A objetivação da Vontade no organismo animal, p. 336).

${ }^{22}$ No original: "...der Wille zum Leben durchgängig an sich selber zehrt...seine eigene Nahrung ist" (Cf. SCHOPENHAUER, A. SW, I, § 27, p. 218). Seguimos a tradução do Prof. Jair Barboza. ${ }^{23} \mathrm{Cf}$. Idem.
} 
natureza e, por outro, abre a possibilidade de se pensar dois tipos de repetição bem como um sentido para a noção de criação na estética schopenhaueriana. Uma repetição eterna de um mesmo processo de objetivação da Vontade em seus fenómenos e uma livre e caótica repetição impulso cego de uma única e mesma Vontade em uma infinidade de mundos possíveis.

A possibilidade de uma dupla consideração do mundo, que descobre que o mesmo é representação e vontade, no nível da representação, é que pode e deve ser utilizada pelos filósofos, segundo Schopenhauer, como chave (Schlüssel) hermenêutica para se compreender (Einsicht) a significação oculta e interna (Innere) dos "processos (Vorgänge) da natureza não dotada de conhecimento (erkenntnislosen)"24. Portanto, se pela física (representação) podemos explicar o mundo, por ela não podemos compreendê-lo; por sua vez, se pela metafísica compreendemos o que ele é - objetivação de uma Vontade em eterna discórdia consigo mesma -, por outro lado, por ela não podemos explicá-lo, mas tão somente usá-la na tentativa de comunicação (Übertragen) entre o que compreendemos internamente e conhecemos exteriormente. Por sua vez, o "lado" do mundo que podemos compreender e o "lado" que podemos explicar não impedem, por si sós, a existência de outras configurações, outras formas de objetivação da Vontade que não podemos acessar a partir da aplicação de nossas formas a priori e de nossa apreensão imediata. Como, então, falar delas? Problema que requereria imprimir uma certa violência ao texto schopenhaueriano e uma certa apropriação da significação da noção de Vontade.

Em resumo, no procedimento analógico, trata-se de uma projeção, na totalidade do mundo ordenado causalmente, daquilo que sabemos quando compreendemos que nossa essência é vontade para, através disso, podermos compreender que aquilo que em nós chamamos vontade é, igualmente, a essência da causalidade, da força gravitacional e elétrica, da excitação nas plantas e dos motivos nos animais. Tal procedimento é que permite a Schopenhauer realizar o Übergang desejado e, finalmente, poder afirmar que: "onde quer que (überall) exista causalidade existe Vontade, sem que esta atue (agiert) jamais sem aquela"25. Portanto, a tese da objetivação da Vontade pressupõe a tese do duplo

${ }^{24}$ Cf. SCHOPENHAUER, A. SW, III, cap. Astronomia física, p. 415.

25 Cf. Ibidem, p. 417. 
conhecimento humano (sujeito e indivíduo), a tese da inteligibilidade inversa e o postulado de uma única e mesma matéria (Materie) como suporte de todo o processo de objetização e objetivação da Vontade. Claro que, para que toda essa maquinaria possa funcionar, Schopenhauer é levado a fazer afirmações que infringem o maior mérito kantiano (distinção entre fenômenos e coisa em si) e o que é dito em toda a obra do autor de $O$ mundo: que a Vontade é, rigorosamente, incognoscível; quando ele diz que: "o que vale (gilt) da Vontade em si mesma (vom Willen an sich selbst) vale também dela sob as condições da experiência e intuição (unter den Bedingungen der Erfahrung und Anschauung)"26, pensamos que ele afirma mais do que pode.

O processo de objetivação descrito acima pretende não apenas justificar a tese de por que a física nunca poderá substituir a metafísica, uma vez que a força, enquanto Idéia, jamais será bem compreendida caso a tomemos por causa mas, sobretudo, tornar viável, na medida do possível, a passagem entre Vontade e Representação e, assim, legitimar aquilo que está, realmente, em jogo: a filosofia enquanto expressão conceitual de um pensamento único. A problemática noção de Idéia é que deveria, mais facilmente, articular as metafísicas de $O$ mundo: metafísica da natureza, do belo e da ética ${ }^{27}$. Quer como força natural, quer como objeto de contemplação artística, quer como expressão da vontade de viver, ela deveria facultar o trânsito de uma metafísica a outra e, assim, articulá-las em um pensamento único. Não entraremos aqui, no entanto, nas dificuldades levantadas por tal procedimento.

\section{Referências bibliográficas}

\section{Obras de Schopenhauer}

SCHOPENHAUER, Arthur. Sämtliche Werke. Editadas e comentadas por Wolfang Frhr. von Lohneysen. Suhrkamp taschenbuch wissenschaft, 2003. 5 vols. (As referências a essa

\footnotetext{
${ }^{26}$ Cf. SCHOPENHAUER, A. SW, II, cap. 24, Da matéria, p. 399.

${ }^{27}$ Segundo Schöndorf, a partir da análise dos Manuscritos, afirma que a noção de Ideia, na filosofia de Schopenhauer, é bastante antiga e sumamente importante, uma vez que ela, juntamente com a noção, posteriormente abandonada, de consciência melhor (besseres Bewußtsein), será responsável pelo pessimismo do autor de 0 mundo, por sua recusa em aceitar o sofrimento como o negativo na existência. Entretanto, dificilmente se poderia aceitar, a não ser, talvez, com muitas ressalvas, a tese de Schöndorf de que o pensameno de Schopenhauer já estaria totalmente constituído em 1818, na primeira edição de 0 mundo (Cf. SCHÖNDORF, H. Der Leib im Denken Schopenhauers und Fichtes, 1982).
} 
edição são indicadas pelas iniciais SW, seguidas pelo número do volume (em algarismo romano) e da página (em arábico)).

. Manuscript remains. Edited by Arthur Hübscher, Translated by E. F. J. Payne, in Four Volumes. New York: Berg, 1989.

. Metaphysik der Natur. Philosophische Vorlesungen über die gesammte Philosophie aus dem handschriftlischen Nachlaß, Teil II. München-Zürich: Pipper, 1984. (Edição de Volker Spierling).

. O mundo como vontade e representação. Trad. M. F. Sá Correia. Rio de Janeiro: Contraponto, 2001. 2005.

O mundo como vontade e como representação. Trad. Jair Barboza. São Paulo: Unesp,

. Cartas desde la obstinación. Trad. Eduardo Charpenel Elorduy. México: Los Libros de Homero, 2008.

Crítica da filosofia kantiana. Trad. Maria Lucia M. O. Cacciola. São Paulo: Nova Cultural Ltda, 1999. (Os Pensadores).

Fragmentos para a história da filosofia. Trad. Maria Lucia M. O. Cacciola. São Paulo: Iluminuras, 2003.

Sobre a filosofia universitária. Trad. Maria Lucia M. O. Cacciola. São Paulo: Martins Fontes, 2001.

Sobre o fundamento da moral. São Paulo: Martins Fontes, 2001.

. Sobre a visão e as cores. São Paulo: Nova Alexandria, 2005.

\section{Outras obras consultadas}

BARBOZA, J. Infinitude subjetiva e estética: natureza e arte em Schelling e Schopenhauer. São Paulo: Unesp, 2005.

BRANDÃo, E. A concepção de matéria na obra de Schopenhauer. São Paulo: Humanitas, 2009.

CACCIOLA, M. L. M. O. Schopenhauer e a questão do dogmatismo. São Paulo: Edusp, 1994.

KANT, I. Kritik der reinen Vernunft. 2 vols. Frankfurt: Suhrkamp Taschenbuch Wissenschaft, 1974.

. Crítica da razão pura. $3^{\text {a }}$ ed. Lisboa: Fundação Calouste Gulbenkian.

. Crítica da faculdade do juízo. Rio de Janeiro: Forense Universitária, 2005; 2010.

. Escritos pré-críticos. São Paulo: UNESP, 2005.

Manual dos cursos de Lógica Geral. Edição bilíngüe: alemão e português. Tradução, apresentação e guia de leitura de Fausto Castilho. Campinas: Editora Unicamp, 2006. 
. Principios metafísicos de la ciencia de la naturaleza. Madrid: Alianza Editorial, 1989.

Prolegômenos a toda a metafísica futura. Lisboa: Edições 70, 1987.

. Realidade e existência. São Paulo: Paulus, 2005.

RUFFING, M. O sujeito do conhecimento - o objeto da ação: a "passagem", identidade e diferença na filosofia de Arthur Schopenhauer. In: Cadernos de filosofia alemã. São Paulo. Publicação semestral do Departamento de Filosofia - FFLCH-USP, Vol. XIII, Jan-Jun. 2009, pp. 11-28.

SCHÖNDORF, H. Der Leib im Denken Schopenhauers und Fichtes. Munique: Berchman, 1982 (Müchener Philosophische Studien, vols. X).

SCHULZE, G. E. Kritik der theoritischen Philosophie. Vol. II. Bruxelas: Culture et Civilisation, 1973.

Recebido: $16 / 03 / 16$

Received: 03/16/16

Aprovado: 06/05/16

Approved: 05/06/16 